\title{
Alternativas para o tratamento em saúde mental. Estratégias psicopedagógicas no atendimento a jovens portadores de distúrbios emocionais severos.
}

\section{Alternatives for mental health treatment. Psycho-pedagogic strategies in therapy for teenagers with severe psychological disturbs}

\author{
Jamil Zugueib Neto*
}

\begin{abstract}
RESUMO
O presente trabalho tem como objetivo apresentar estratégias clínicas como alternativas ao internamento de crianças e jovens acometidos de distúrbios emocionais severos. Sublinha-se a indissociabilidade que deve haver nessas ações entre a pedagogia e a intervenção psicoterapêutica, aqui representada pela orientação psicanalítica. Após a ilustração de um caso atendido em escola especial, fundamentam-se os argumentos a partir das proposições alinhavadas na $2^{\mathrm{a}}$ e $3^{\mathrm{a}}$ Conferência de Saúde Mental do Ministério da Saúde. São propostas políticas de criação de espaços mais abertos, inseridos no Sistema Único de Saúde (SUS), que se harmonizem com as demandas sociais, incentivando-se posições para um pensamento contrário a uma visão da psiquiatria tradicional.

Palavras-chave: doença mental, adolescentes, psicopedagogia.
\end{abstract}

* Doutor em Psicologia. Professor do Departamento de Psicologia da Universidade Federal do Paraná. E-mail: jzugueib@ufpr.br 


\begin{abstract}
The present work aims at showing clinic strategies as alternatives to the admission at psychiatric hospitals of children and youngsters suffering from severe emotional disturbance. Concerning these actions, we emphasize the need of associating pedagogy and psychotherapeutic interventions, here represented by psychoanalytical orientation. After presenting a case that happened at a special school, our observations are based on the $2^{\text {nd }}$ and $3^{\text {rd }}$ Ministry of Health Mental Health Conference proposals. Such proposals are political and aim at creating opener spaces, included in the Single Health System, in Brazil, according to social demands and stimulating thoughts opposed to the traditional psychiatric point of view.
\end{abstract}

Key-words: mental illness, adolescent, psycho-pedagogy.

Duas considerações preliminares movem o presente trabalho. A primeira é a de que o processo de aprendizagem de um indivíduo portador de distúrbios psicológicos, seja qual for a sua etiologia, só poderá ser efetivo aliandose a intervenção psicoterapêutica com a ação pedagógica. Isto é, em se tratando seja de inserção escolar ou de inserção social, não há estratégias suficientes se tomadas em práticas isoladas. É preciso insistir no trabalho conjunto e interativo do pedagogo e de outros profissionais de áreas afins.

A segunda, e na qual pretendo me estender nesse artigo, é de que é viável e humanamente desejável incrementar o atendimento do portador de distúrbios emocionais em bases institucionais mais abertas e mesmo opostas àquelas do tratamento psiquiátrico tradicional, calcado no confinamento social e na maioria das vezes somente sob intervenção quimioterápica. Para resgatar alguma possibilidade de crescimento, há que se ensaiar permanentemente estratégias de tratamento que rompam com o isolamento e a marginalização a que historicamente são predestinados tais indivíduos.

Desde que a criança com necessidades especiais ocupa um lugar desacreditado, suas capacidades intelectivas, psíquicas e sociais quase sempre serão avaliadas tendenciosamente, quando não ignoradas. O mesmo ocorre com suas possibilidades de desenvolvimento adaptativo ou transformação interior.

A partir deste lugar ocupado, uma marca lhe é impressa. Um estigma depreciativo imposto pelos outros a demarcará nas redes das relações interpessoais, passando este registro a sobressair-se sobre o todo de sua personalidade, o qual, por sua vez, estabelecerá uma forma de ser tratado. 
O estigma, portanto, cria condições para que um indivíduo seja visto de uma maneira congelada, impedindo que outros de seus atributos possam ser reconhecidos. Esta situação toma maior relevância quando o situamos dentro do contexto familiar e educativo.

Para que a criança se desenvolva de uma maneira sadia, é fundamental para ela uma inter-relação rica em experiências, que lhe dê condições para testar por ensaios e erros a conquista de sua autonomia. $\mathrm{O}$ apreço e a consideração são condições básicas para a construção de uma auto-imagem positiva, que lhe dará maior segurança nas resoluções dos possíveis conflitos com que ulteriormente venha a se deparar.

Em situações de famílias portadoras de crianças que apresentam disfunções psicológicas, tal ambiente invariavelmente ficará comprometido por uma série de razões. Em sua forma mais branda, podemos encontrar pais equilibrados e maduros emocionalmente para perceberem suas frustrações quanto ao filho que têm, ao mesmo tempo que se vêem necessitados em envidarem maior atenção para lhe possibilitar uma educação adequada. Essa tentativa exigirá esforços para suportar os desgastes emocionais quando sucessivos fracassos se repetirem em situações de novos aprendizados ou correções de comportamentos inadequados.

Mas uma segunda conseqüência deste panorama traçado toma caminhos mais funestos, imbricam-se aos primeiros e travestem-se de variadas formas de comportamento. São as feridas narcísicas impingidas aos pais e difíceis de serem suportadas, pelo nascimento de um filho deformado, quanto àquilo que se acalentava desde há muito tempo em suas idealizações referentes à constituição de uma família.

A cada fracasso do filho, e a cada emissão de uma conduta inadequada, processa-se uma estocada ao amor próprio dos pais. Sua manifestação desdobra-se em comportamentos e emoções variados, desde a indiferença, angústia, agressão, a sentimentos de impotência, culpa ou devotado amor superprotetor, que geralmente é uma forma de os pais transformarem o ódio em seu oposto. Este mecanismo serve para lhes livrar da culpa que sentiriam em não cumprirem a imagem de pais que construíram.

O desprestígio sofrido e a relação congelada que tem ação sobre o pequeno indivíduo só poderão redundar em uma autopercepção negativa e falha de si.

Freqüentemente em famílias que possuem crianças alteradas, estas acabam transformando-se em bode expiatório das mazelas e crises atravessadas pela novela de sua família, quando já não são elas mesmas a expressão da doença grupal. Como suas necessidades básicas de reconhecimento e amor 
não são satisfeitas, um comportamento de revolta é esperado. Esta reação poderá não ser somente uma agressão franca, mas poderá travestir-se em outros comportamentos, tais como: resistência ao aprendizado, atitudes infantilizadas, condutas bizarras, fugas ou outras inadequações sociais. Desta forma, delinear-se-á um circuito retroalimentador - mais insatisfações aos pais que lhe respondem com novas agressões, as quais são rebatidas pelo filho com novas inadequações.

Um indivíduo portador de um distúrbio psicológico sempre guarda algo de resgatável em seu caminho de desenvolvimento ao mundo externo, pelo que ele poderá fazer vínculo e estabelecer relações de alteridade, fundamentais à construção de sua identidade.

Infelizmente, estas oportunidades não se criam, tanto em seu ambiente familiar quanto em instituições encarregadas de sua "educação", mais envolvidas em conter sua loucura do que desenvolver um programa individualizado, de aproveitamento de suas características sadias.

Também em função dos conflitos emocionais resultantes da carga negativa sofrida em casa, e associadas à desorientação advinda de seu próprio quadro nosológico, suas capacidades de compreensão e resolução pragmática ficam obliteradas ou pouco desenvolvidas. Isso resulta, como vimos insistindo, em uma situação que em nada auxiliará seu crescimento, quando não configurar situações patogênicas que concorrem à cronificação de seu comportamento desajustado.

A partir dessa explanação, pretendo contribuir neste artigo com a proposta das novas políticas de Saúde Mental que vem sendo defendida há mais de duas décadas pela $\mathrm{OMS}{ }^{1}$ e, no Brasil, desde a $1^{\text {a }}$ Conferência Nacional de Saúde Mental, em 1987, marco inicial para as reformas psiquiátricas nacionais e que continuam a partir de várias experiências, mobilizando profissionais de referências epistemológicas diversificadas, dentre elas a Escola Inclusiva. Que se diga tratamento ou escolarização de Jovens Portadores de Distúrbios Emocionais Severos (JPDES, sigla que adoto neste artigo), seus objetivos só serão atingidos (proposta, aliás, nada recente) se essa clínica associar intervenções psicoterápicas e programação pedagógica. Colocarei em paralelo a seguir as duas estratégias, para depois dar um exemplo que realça a indissociabilidade de ambas no tratamento em saúde mental.

${ }^{1} 1^{\circ}$ Encontro Latino Americano de Alternativas à Psiquiatria, México, 1981, Criação da Rede Alternativa de Psiquiatria, Bruxelas, Bélgica,1975, sem falar da Convenção de Alma Ata no Cazaquistão em 1975. 


\section{A estratégia pedagógica}

O processo de apreender a realidade, transformá-la e transformar-se requer uma série de operações mentais, que um JPDES não consegue realizar, ou, na melhor das hipóteses, seu desempenho será deficitário.

Pela gnose o indivíduo modifica e suplanta a si e à sua realidade circundante. A ação pedagógica, ao transmitir o como fazer da ação humana, submete-o a uma ordem social possibilitando-lhe a identificação com o semelhante. São os primeiros passos na direção do ser cultural. Educar consiste então em ensinar, no sentido de mostrar, de estabelecer sinais, de marcar como se faz o que se pode ser feito. (PAIN, 1992, p. 18).

Sua intervenção se dá por meio de técnicas criadas para proporcionar ao sujeito a apreensão e controle consciente de operações intelectuais que possibilitem o controle sobre o meio. Na medida em que a ação pedagógica ordena suas capacidades, estanca o instinto e instrumentaliza a desorganização. Esta ação se dá exclusivamente na parte consciente da personalidade, exercitando as capacidades de atenção, memorização, organização, planejamento, dedução, discriminação, generalização, entre outros, possibilitando ao eu (ego) adotar um comportamento racional e planejado, ou engendrar uma operação mental necessária em um momento específico, que, por falta de oportunidade ou treino, não se realizava. A ação pedagógica incita novos padrões mentais, mas esses nem sempre vêm à luz, por se constituírem de puras possibilidades, pois estão emaranhados na trama de seus complexos inconscientes.

De acordo com a visão da psicanálise, o processo educacional visto em sua totalidade vem a ser a canalização e ordenação das pulsões sexuais e agressivas para os fins de sobrevivência e o submetimento do indivíduo a uma lei social de convivência e adaptações aos ideais de sua cultura² ${ }^{2}$.

Se perguntarmos também quais serão os objetivos do final de um processo analítico, constataremos que são os mesmos buscados pela pedagogia. Havendo apenas um cuidado quanto à questão da "adaptação aos ideais de sua cultura", pois ela cuida antes do favorecimento do resgate pelo sujeito de sua especificidade, da assunção de seu próprio desejo, libertando-o muitas vezes das idealizações culturais de seu meio.

${ }^{2}$ Freud em Formulações sobre os dois princípios do funcionamento mental, 1911. A educação é descrita como um incentivo ao controle do princípio do prazer. 


\section{A estratégia da intervenção psicológica}

A intervenção psicológica se justifica a partir desses três aspectos:

1 - A inteligência e a curiosidade estão submetidas ao terreno inconsciente - lugar das pulsões e do desejo -, que torna fértil ou árido o desabrochar da ação do conhecimento.

2 - É necessária a introdução de terceiros - os pais, outros técnicos além do pedagogo e a instituição.

3 - É imprescindível dispor de recursos metodológicos e técnicos eficientes para o manejo de formações inconscientes que aflorarão no decorrer do processo.

Então, como estratégia geral de abordagem, devemos colocar em paralelo e acoplados os dois processos.
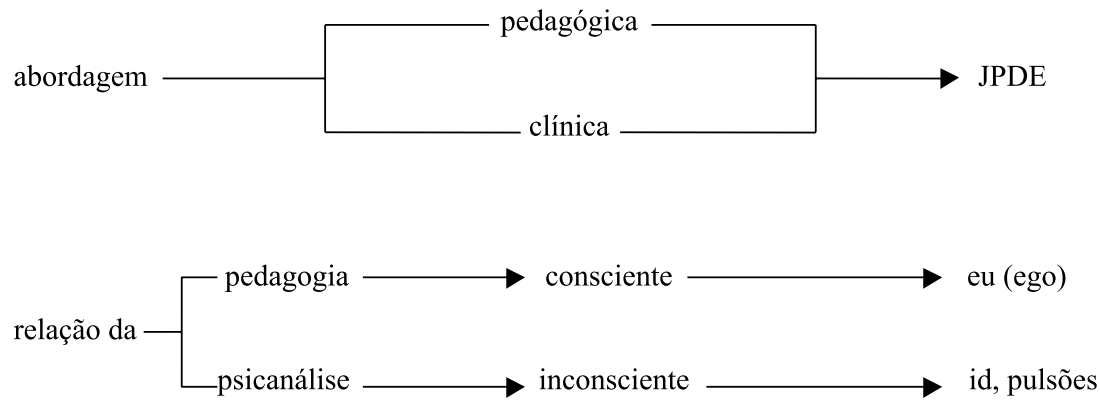

Não se quer reivindicar que somente a psicanálise é a orientação teórica que pode produzir efeitos positivos na intervenção psicopedagógica, apesar de se crer que só ela pode atingir níveis mais profundos na intervenção e, portanto, na alteração subjetiva. Uma abordagem psicológica poderá seguir diferentes fundamentações teóricas para abordar o JPDE, o que naturalmente refletirá uma concepção de funcionamento da personalidade e de seus mecanismos adaptativos. Feita essa remarca, adoto a psicanálise como referencial de uma linha de intervenção.

O processo da psicanálise é distinto ao consistir "em remontar à fonte infantil do problema, quer dizer, às fixações libidinais que entravaram o desenvolvimento, para liberar do recalque as forças psíquicas a fim de que estas possam então entrar no processo de maturação do qual haviam escapado até então" (MILLOT, 1987, p. 52). O seu campo de ação vai se estruturar então no 
inconsciente, fonte de energias pulsionais e do recalcado - nas representações de vivências insatisfatórias e traumatizantes, engavetadas nos primeiros capítulos de vida de um sujeito.

E, para que se dê marcha a este processo, há que se preencher condições bem precisas, resumidas pela expressão "situação analítica", que variam segundo o tipo de trabalho a ser realizado e graus de patologia, mas que podemos considerar completa quando estiver composta pelos seguintes itens:

1) A posição de escuta do analista e sua regra de abstinência quanto a uma possível diretividade.

2) O enquadre: forma de relacionamento que visa somente à atenção, à escuta e à análise, ou seja, ao tratamento do analisante, é visar à possibilidade de o paciente configurar o espaço da relação pelas variáveis que dependem de sua personalidade e comportamento;

3) A regra fundamental: o analisante deve falar tudo o que lhe vem à consciência, evitando a censura e o controle consciente de seu discurso.

4) A relação transferencial: relação intensa e de verdadeiro enamoramento que o analisante estabelece com o analista e que reproduz vivências passadas e de modelos de relações afetivas vividas anteriormente (os pais e seus representantes). O tratamento culminará com a sua resolução.

5) A interpretação: é a procura da significação da fala e do sentido simbólico do comportamento do paciente a partir do referencial teórico do analista. Será refazer história (do Édipo) e significação de suas relações endogâmicas e seus desdobramentos em seu trajeto subjetivo. Ela vai possibilitar ao paciente um novo saber, sobre si e sobre suas pautas de conduta bizarras, um mais além da escanção consciente, para onde se alojou os determinantes de sua problemática e que se expressam na angústia e na repetição por meio da metáfora e do deslocamento, da metonímia e do condensamento.

É tarefa delicada explicar o tratamento psicanalítico. "A diversidade das situações e das evoluções terapêuticas desafia a generalização" (LAGACHE, 1966, p. 84). A cura advém de um tratamento específico, em que a palavra possibilita o encontro com o conflito inconsciente. Por meio dela, os sintomas travestem-se de diversas formas e cabe ao analista decifrar a sua mensagem. Baseando-me em LAGACHE (1966), ao final de um processo bem sucedido, o paciente terá condições de ajustar as suas aspirações às suas possibilidades e à realidade. Ele terá capacidade de se conduzir prevendo os efeitos longínquos da sua conduta e de trabalhar para a realização de um plano de vida. 
As suas relações sociais serão mais fáceis e suas condutas destrutivas ou exageradamente conformistas serão abandonadas.

A intervenção da psicanálise no processo da socialização primária vai além do aprendizado puramente cognoscitivo, pois abre o caminho até então entravado para um vínculo emocional significativo com seus Outros significativos. Nas relações objetivas, esses últimos estabelecem a mediação para o mundo, modificando o jovem pela marca que lhe imprimem, pois as novas introjeções só se realizam quando há identificação e esta só ocorre quando caem os fantasmas que congelavam seu acesso a esse Outro. Essa abertura enfim vai possibilitar a construção de uma nova subjetividade.

\section{O trabalho multidisciplinar}

A combinação das duas estratégias é uma condição a conquistar. Daí a oportunidade de se rever lições emergidas de práticas tentadas.

A partir de sua experiência, MANNONI (1990) procura inicialmente diferenciar as duas abordagens:

Na primeira, a pedagogia se organiza para uma ação adaptativa em uma criança débil e psicótica, e, noutra, a psicanálise interroga-se sobre sua representação, visto que ela sempre encontra-se alhures, isto é, longe de onde se nos apresenta, perdida que está em uma trama imaginária. Sua arte (a da psicanálise), é poder interpelá-la neste local distante, que nos escapa e foge de si. Sugere então a psicanalista repensar a pedagogia à luz das descobertas freudianas.

O educador deve repensar o que lhe foi passado em nossa tradição cultural e a opor neste ensino recebido uma reflexão na sua prática: "Estou aqui para transmitir um saber, e o que é que se transmite quando se crê ensinar?"

E é por não colocar em questão o desejo, que o educador situa-se em posição diferente do analista. Este se interessa por tudo o que toca a relação com a verdade construída por seu paciente. $\mathrm{O}$ educador atravessado pelo saber descoberto pela psicanálise poderá encontrar mais fácil a palavra justa às perguntas verdadeiramente genuínas de seu aluno. Ele poderia refletir melhor se tivesse a percepção adulta, concernente à criança que existiu dentro de si.

Por outro lado, um analista que somente se interessa pela análise individual fica fechado e surdo para o que acontece na Instituição, e não se dá conta 
de que ela é um sistema que se é obrigado a interrogar. Se a pretensão não é transformar toda a Instituição terapêutica por si mesma, pelo menos deve-se tomar a precaução para que o trabalho efetuado no tratamento não seja destruído na Instituição, já que muitas aproximam-se de estruturas familiares psicotizantes. E por isso ele deve prestar atenção aos seus mecanismos interativos entre a equipe e contribuir para que estes tomem consciência de suas contradições e nódulos conflitivos que possam obliterar uma complementação de funções na intervenção psicopedagógica.

Por outro lado, os educadores de formação tradicional, baseados na crença da origem fisiológica das perturbações emocionais, visam essencialmente a realizar aprendizagens de compensação, que se bastariam a uma adaptação relativa. Neste sentido, são levados a acreditar saber de todas as necessidades da criança, sem perceber que muitas vezes esses interesses são, antes de tudo, seus. Como adultos que são eles darão à criança as sua próprias representações do mundo da infância, ignorando o que ocorre no imaginário infantil. E desta maneira ignoram a criança como sujeito de uma palavra ou de um desejo que nela se embute.

É em uma posição que de certa maneira o adulto se renuncie, situação aí então não-dual, é que vão criar-se possibilidades de o desejo nascer entre educador e a criança. "Ainda é preciso para que a situação se estruture que o desejo possa ser simbolizado, quer dizer, que alguma coisa se organize em relação a uma palavra e permita na criança a criação do discurso inconsciente, com seus efeitos de sentido", (MANNONI, 1990, p. 241). É por aí também que não se deve incentivar um comportamento imitativo, uma forma de engodo. Para permitir um processo de identificação estruturante, a criança deve poder sentir-se distinta do outro e não colada ao exemplo maciço da pessoa do educador.

Acompanhar na Instituição a aventura da "escolarização" leva a repensar todo o problema da aprendizagem em função da natureza dos obstáculos encontrados. Um deles é a inter-relação das dificuldades da criança com o efeito que causam no inconsciente do adulto. Tempo deve ser consagrado a esta relação, suporte das angústias da criança. Reduzem-se assim os riscos de despersonalização e crises depressivas no técnico quando estão expostos à agressividade e apatia de certos tipos de criança.

O analista pode lhe auxiliar na "compreensão de uma situação cujo sentido lhe escapa, na medida em que se encontraria implicado nela diferentemente do que sabia" (MANNONI, 1990, p. 243).

Neste sentido percebe-se a transformação que a pedagogia sofre.

Em tal sinuoso caminho não há como esquecer outros profissionais da Instituição, como o pessoal administrativo. Nesta proposta, não há como 
esquecê-los, pois a interrogação analítica deve se colocar em todos os níveis da estrutura institucional. A partir daí, todos estarão aptos a fazer suas descobertas.

Psicanalistas e pedagogos devem atuar como guardiães de um funcionamento saudável e aberto para o questionamento da instituição. É daí que o educador pode ensinar e o psicanalista pensar em seus tratamentos individuais.

Eles não devem coexistir como disciplinas diferentes, ao lado de psicomotricistas e fonoaudiólogos, realizando uma divisão da criança em especialidades múltiplas. A contribuição da psicanálise em projetos psicopedagógicos só tem sentido se puder partir de um ponto em que o esclarecimento analítico vai permitir complementaridade, modificando o próprio dizer pedagógico.

Depois de colocarmos nossas posições quanto à inter-relação dos campos da pedagogia e da psicanálise na clínica do jovem portador de distúrbios emocionais, ilustro com um caso tratado nos moldes defendidos nas linhas acima.

\section{Caso Pedrinho}

Intervenção psicopedagógica com sentido de inserção ou reinserção escolar ulterior

Pedrinho contava 5 anos quando entrou para a escola, onde foi integrado a uma turma de três crianças, onde o objetivo principal era fazer um laço com a professora e entre elas mesmas. Possuíam distúrbios severos de retraimento social e de comunicação. O trabalho era feito através da ambientoterapia, em que todos os recursos do ambiente são utilizados como recursos terapêuticos. Utilizava-se recursos de estimulação sensório-motora - trabalhos com barro, água, areia. Exercícios motores - correr, saltar, pular em direção ao ser humano. Presentes em todas as estimulações, o banho de palavras - numa tentativa de que algo do simbólico se inscrevesse. A responsabilidade pelo trabalho grupal foi de uma psicóloga, durante um ano. 


\section{Primeiro ano}

Na sua chegada à Escola Especial, Pedrinho não se comunicava, não permitia a aproximação física das pessoas. Caso isso ocorresse, entrava em crise de gritos. Quando entrava em pânico, beliscava o próprio peito até sangrar. Outras vezes, batia seguidamente a cabeça na parede. Perambulava sem rumo pela sala, não atendia quando era chamado. Em dado momento, passou a cuspir nos quatro cantos da sala e nos objetos com os quais se relacionava.

Antes de sentar numa cadeira, cuspia nela e esfregava em seu assento. Ao aceitar uma bola para brincar, primeiro cuspia e esfregava sua secreção. Mais tarde, passou a urinar pequenas quantidades nos quatro cantos da sala, para depois passar o dia bem, sem crises de grito ou auto-agressão.

Após algum tempo, começou a apresentar crises quando algo do seu ambiente era modificado. Por exemplo, uma janela que abria, uma banqueta que era mudada de lugar após sua entrada na sala. Neste momento, Pedro já apresentava olhar dirigido, permitia aproximação de pessoas, empreendia a exploração de objetos (sempre após cuspir), mas não desenvolvia uma atitude lúdica, sorria para as pessoas conhecidas, aceitava os trabalhos propostos. Estabelecia trocas, mostrava compreensão da linguagem, reagindo às solicitações da psicóloga. Chegava a articular algumas palavras.

Ao final do primeiro ano, já não mais cuspia.

Durante este período, programou-se um roteiro de atendimento que favorecesse a constituição de um sujeito, efeito da linguagem.

\section{Segundo ano}

Pedro é transferido para outro grupo, que segue os objetivos do grupo anterior, porém uma aprendizagem sistemática começou a ser inserida. Foram trabalhados: discriminação de cores, forma, distância, tamanho, percepção auditiva, coordenação viso-motora; iniciação do raciocínio matemático com trabalhos de seleção, quantidade e conjunto.

A esta altura, Pedro voltou a cuspir e urinar na sala. A interpretação dada é a de que ele necessitava demarcar novamente seu ambiente externo com suas excreções, atividade que durou pouco tempo. Em seguida, deu mostras de iniciar um vínculo com a nova psicóloga e os novos colegas. Por pouco tempo ainda, voltou ao comportamento de que nada em seu ambiente pudesse ser mudado após a sua chegada. Ao adaptar-se à nova sala e ao novo grupo, iniciou, de forma mais clara, o uso da linguagem. No princípio, nomeava apenas os objetos, em seguida passou a construír frases curtas pedindo o que desejava. Interessante observar que em sua casa nada falava. A mãe, ao 
saber que Pedro era capaz de falar, caiu em uma crise de choro. Ao ser inquirida das razões que atribuía ao fato de a criança falar na escola e não em casa, se deu conta que em casa falava por ele, adivinhando suas necessidades e desejos, o que não dava à criança razão nenhuma para se comunicar. Nunca ela conseguiu suportar a ansiedade de esperar por ele sentir falta de algo, para que pudesse pedir.

Passado algum tempo, Pedro começou a se interessar pela diferença sexual. Manipulava bonecas perguntando sobre seu sexo, observando com o mesmo interesse meninas e professores. Perguntava por que elas não têm pênis, com poucas palavras e muita mímica. Em seguida, com gestos imitando uma tesoura, perguntava se iriam cortar seu pênis. A professora apaziguava-o e assinalava que ele é um homem como o seu pai, e que as mulheres são diferentes. É bom sublinhar que esta temática foi explorada ao longo de alguns meses. Depois desses assinalamentos, ele voltou com a questão de que o pênis de seu pai era maior e mais grosso. Quando a psicóloga lhe disse que ele crescerá e seu pênis também, ele passou a:

a) Subir em cadeira, mesas e armários, procurando o tamanho exato que poderia atingir.

b) Resolvida a questão de sua futura estrutura corporal, passou a querer calcular o tamanho do seu pênis.

c) Resolvida a última questão, passou a querer calcular agora o seu calibre.

Após todos esses questionamentos, essas explorações e suas conclusões, que parecem ter sido satisfatórias, adentrou definitivamente no universo da linguagem e desenvolveu facilmente seu processo de aprendizagem, mantendo neste percurso novo uma série de comportamentos obsessivos-compulsivos.

Por exemplo: os lápis deveriam estar todos apontados e equilibrados em cima da mesa; deitava-se em almofadas da sala de aula por 10 a 15 minutos antes do início dos trabalhos escolares. Assinalado e também impedido (no caso das almofadas) de repetir estas condutas, é-lhe assegurado que o dia transcorreria bem, sem que ele necessitasse desses rituais de pacificação. Nesta altura, já conseguia manter um diálogo, expressando-se de uma maneira clara, fazendo ligações entre pronome, verbo e substantivo, usando o pronome na primeira pessoa. Terminou este ano dando-se conta de que o que é falado pode ser escrito, intuindo a relação fonema - grafema. Pedia que lhe fossem lidas historinhas, que escrevessem o seu nome, o do seu pai e de sua mãe e tentava copiar. E assim encerrou-se esta etapa. 


\section{Terceiro ano}

No início deste novo ano, cuidou-se de se fazer uma avaliação para se verificar se Pedro estaria apto a ingressar em uma classe de aprendizagem sistemática de lecto-escritura.

A seguir mostram-se o resultado dos testes aplicados. De cores primárias e secundárias: boa discriminação de formas geométricas e coordenação motora fina (recorte e colagem).

Relações espaciais:

- Dificuldade em relação aos seguintes conceitos: ao lado, na frente, em cima, fora

- Tem noção de: atrás, embaixo, dentro, entre

- Com relação ao tamanho: dificuldade com maior

- Conceito de distância: perto e longe

- Conceito de quantidade: muito, pouco, menos, mais

(O.K.)

- Conceito de espessura: grosso e fino

- Conceito de largura: estreito, largo

- Conceito de altura: alto e baixo

- Conceito de comprimento: curto, comprido

- Diferenças - não percebia

- Semelhanças - sim

- Lateralidade - tinha estabelecida direita - esquerda em si mesmo, no outro e em relação à realidade representada graficamente.

- Não tem seqüencialização na sucessão de eventos.

- Memória auditiva - dificuldade em reter e executar duas ordens simultâneas.

- Coordenação viso-motora - excelente desempenho.

- Linguagem oral - consegue emitir fonemas.

- Coordenação dinâmica geral - boa em seus aspectos: equilíbrio - estático e dinâmico, movimentos isolados e amplos do corpo.

Frente a estes resultados, Pedro é colocado em uma turma de alfabetização e de trabalho de desenvolvimento do raciocínio lógico matemático. Reagiu bem ao programa, terminando este ano lendo e escrevendo as vogais, as junções de vogais, a numeração até o número cinco. Foi capaz de elaborar um discurso narrativo (criar histórias), reproduzir uma história que lhe seja contada, interpretando-a. Seu vocabulário é cada vez mais suficiente para expressar seu pensamento. Apresentou excelente coordenação viso-motora.

Quanto aos aspectos sociais, observou-se sua participação em jogos grupais, demonstrando compreensão e respeito às regras. Possui amigos, é 
cooperativo, não agressivo, é alegre e não retraído. Sabe esperar sua vez na participação em atividades grupais.

\section{Quarto ano}

Pedro é matriculado oficialmente em uma turma da primeira série do primeiro grau (na mesma escola).

Acompanhou muito bem as etapas do currículo, sendo necessário que se aumentasse o nível de exigência nos assuntos tratados, dada a facilidade com que aprendia, e o interesse que demonstrava por questões teóricas suscitadas pelas leituras. Não lhe bastava o conhecimento oferecido pela professora e pelos livros didáticos. Queria mais informações e detalhes, indo procuralos em enciclopédias e nos livros da biblioteca de sua casa. Exigia compulsivamente da professora informações complementares, parecendo querer esgotar totalmente o tema abordado. Seu comportamento ritualístico se acentuou. Agora mostrava uma compulsão no controle do tempo, fazendo-o olhar repetidamente o relógio, somada a uma obsessão pela quantidade. Por exemplo: quantos clips há em uma caixa? Conferia se haveria realmente quarenta palitos em uma caixa de fósforos. Quantos fios poderia haver em uma mexa de cabelos, etc.

Em paralelo, retraiu um pouco sua convivência com amigos. Frente a isso, foi intensificado o trabalho psicoterapêutico com a mãe, e, em separado, com o filho.

Mas termina o ano com bom convívio social novamente. Os rituais arrefecem sua intensidade. Pedro é encaminhado a uma escola regular, encerrando assim o atendimento especializado. Acrescenta-se aí que houve bastante resistência por parte da família quanto à aceitação do ingresso no ensino regular. Havia temores de que o quadro patológico retornasse.

Neste momento, a família foi assistida muito de perto, objetivando mostrar que o trabalho em escola especial não tem por finalidade o asilamento e a proteção indefinida da criança. O objetivo era prepará-la estruturalmente para as adversidades da vida, inerentes ao destino da cada ser humano, mesmo para uma pessoa que tenha sofrido na constituição de sua personalidade. Os temores de abandono e os desejos de proteção da família foram trabalhados até que fossem melhor elaborados por todos os seus componentes.

O quadro da escola que atuou no caso "Pedrinho" constituiu-se de:

- uma psicanalista, chefe de equipe;

- uma psicopedagoga;

- dois professores; 
- um acompanhante terapêutico (atividades extra-classe);

- um psicólogo.

O regime de trabalho, neste caso, implicou na permanência diária de um período escolar do jovem paciente.

\section{Comentários}

Este exemplo ilustra a alternativa proposta. Depois de elaborados os problemas psicológicos por intervenção analítica, desobstruíram-se os canais que o levaram para a aprendizagem e a socialização, propiciando sua entrada definitivamente no universo simbólico, quando resolveu questões fundamentais de seu período Edipiano, e concomitante complexo de castração, a sexualidade e sua identificação sexual. Passou a estabelecer a partir daí, e gradativamente ao longo dos dias, contatos mais significativos e diferenciados com o mundo social. Mitigada alguma ansiedade com respeito à sua sexualidade, esta energia libidinal deslocou-se para uma curiosidade intelectual impressionante. Nada o satisfazia nas explicações dadas em sala de aula. Em sua casa, consultava enciclopédias tentando "ao máximo esgotar o assunto". Com esta fome de conhecimentos podemos avaliar a força do seu empuxo libidinal. Hoje em dia, ele freqüenta a escola regular. Realizando-se uma análise fina, nota-se que sua qualidade emocional o diferencia de outros jovens. Mas ele foi inserido na escola regular e nela pode participar das diversas possibilidades, estimulações e conflitos pelos quais pode passar um aluno normal, podendo compartilhar das infindáveis possibilidades enriquecedoras que a vida em sociedade pode lhe oferecer. A família foi acompanhada a todo o momento e a atenção psicológica certamente continuou na nova escola.

O exemplo mostra claramente a correlação da aprendizagem, a busca do conhecimento encetada pelo garoto, o seu quadro patológico e o tipo de vínculo que seus pais estabeleciam com a criança. A mãe que pensava e falava por Pedrinho foi assistida por um analista e foi possível trabalhar suas fantasias com respeito ao seu papel de esposa, mãe, e a superproteção dedicada a seu filho com necessidades especiais. Sem dúvida, este foi o início de um debate interior mais amplo que a levou a saudáveis transformações interiores, que necessariamente carregaram o outro pólo da parelha conjugal a entrar nesse processo.

O exemplo, além de mostrar o itinerário da preparação da estrutura cognitiva pela psicanálise, também serve de ilustração sobre o funcionamento metodológico de uma escola voltada para o JPDE, uma equipe multidisciplinar discutindo e trocando informações para a definição das táticas a serem usadas em cada período do processo. Sem que se perdesse a iden- 
tidade de cada profissional, o chefe da equipe, no caso um psicanalista, coordenava e dava substratos ao educador para melhor afinar e instrumentalizar a sua estratégia. Por outro lado, o professor fornecia o resultado de suas intervenções e o comportamento geral do aluno em sala de aula, os quais eram processados novamente junto aos outros membros da equipe. Testes e outras sondagens eram requisitados em momentos em que se precisasse.

Queremos salientar que esta instituição clínica-pedagógica que atendeu o caso "Pedrinho" - a Escola Terapêutica de Curitiba - funcionou em nossa cidade durante 10 anos (1977-1987) e que chegou a contar em sua equipe com cinqüenta elementos entre estagiários, acompanhantes terapêuticos, psicólogos, pedagogos, fisioterapeutas, etc., além de controles medicamentosos realizados por médicos especialistas de acordo com as necessidades individuais. Com este quadro de profissionais, chegou a atender até 100 crianças e jovens simultaneamente, com seus currículos diferenciados e todas as atividades complementares que uma escola poderia oferecer.

\section{Considerações finais}

A Lei n 9.394, cap. V de Diretrizes e Bases da Educação Nacional define educação especial como "modalidade de educação escolar oferecida preferencialmente na rede regular de ensino, para portadores de necessidades especiais" e sua oferta é dever do Estado (art. 58,§ $3^{\circ}$ ). A LDB prevê currículos, métodos e organização específicos para o atendimento adequado dos alunos especiais. A sua tônica é a integração desses alunos à escola regular. A proposta defendida pelo Estado da Escola Inclusiva propõe um novo modo de se encarar e intervir: propõe mudanças de valores e atitudes na sociedade e na condução da própria educação escolar. Ora, mudar atitudes e valores sociais é tarefa de envergadura que, sabe-se, requer além de tempo (décadas?) toda uma ação que englobasse diversos setores da sociedade. Esta proposta deve ser encarada como uma postura que o pessoal envolvido deve adotar na sua prática cotidiana e como um projeto grupal permanente de busca, de prática, reflexão e de utopia, pois "a prática da inclusão propõe um novo modo de interação social, no qual há uma revolução de valores e atitudes, que exige mudanças na estrutura da sociedade e da própria educação escolar”, segundo documento da Secretaria de Estado da Educação, citado por KAFROUNI e PAN 
(2001). Projeto esse que se superpõe e é desdobramento das propostas já oficializadas nas $2^{\mathrm{a}}$ e $3^{\mathrm{a}}$ Conferências de Saúde Mental (1992 e 1996) do Ministério da Saúde associado ao Ministério da Educação.

Por isso passo a defender diretamente o meu argumento: Como atender um jovem com distúrbios de nível de comprometimento igual ao do exemplo acima? Certamente que a escola tradicional como alternativa para o hospital psiquiátrico não é a opção cabível. Há que se pensar em espaços em que seja possível a discriminação dos casos para em seguida encetar-se a estratégia de sua abordagem como primeira fase de sua inclusão na escola de ensino regular. Que seja uma alternativa aos Centros de Atenção Psicossocial (CAPS) do Sistema Único de Saúde (SUS) e que possibilite respostas terapêuticas mais complexas exigidas no atendimento a esse tipo de jovem.

Que seja uma instituição mais aberta para novas propostas de vínculos institucionais e para pensar em novas estratégias a cada vez que seja necessário mudar, que envolva pessoal técnico variado, inserido nas demandas regionais e que busque a participação da família e outros serviços que a comunidade possa oferecer. Que discrimine a especificidade de cada quadro nosológico e que organize as suas estratégias de intervenção em função das necessidades da pessoa e não somente de sua doença.

Esta proposta se baseia no paradigma de que a complexidade e seriedade das doenças mentais requer, em seu atendimento, prevenção, reabilitação e a cooperação sistemática dos quatro tipos de protagonistas que intervêm no processo: o indivíduo, a família, a rede ou conjunto de serviços de saúde mental e a comunidade, todos eles em cooperação com o Estado.

Essas diretivas se harmonizam na política da des-hospitalização da atenção em Saúde Mental e na desinstitucionalização das práticas assistenciais. O que se entende por isso?

Não se propõe o total desaparecimento dos hospitais psiquiátricos. Mas sim, reciclá-los, com novas propostas mais democráticas, mais significativas para os internados, oportunizando a multidiversidade das suas experiências com experiências comunitárias. Por desinstitucionalização entendo toda proposta que, em seus objetivos, já tenha em mira por princípio, de que em nada se concorrerá para um congelamento das relações propostas e modelos de atendimento. Mas que se vislumbre sempre a possibilidade de mudança ou engendramento com outras formas e iniciativas, nunca se associando, porém, a estruturas burocráticas que possam atravancar ou comprometer, ideologicamente, o seu próprio desenvolvimento.

Luta antimanicomial não consiste necessariamente em pôr abaixo e arrasar materialmente o frenocômio. Mas sim, refletir e pôr em prática proje- 
tos que transformem a maneira de se comunicar e as práticas dominantes. Que se associe com outros programas, organizações e movimentos da sociedade civil, criando mecanismos de avaliação do serviço psiquiátrico e considerando as realidades locais, pois a complexidade das questões que envolvem o campo da Saúde Mental exige a construção coletiva de práticas e saberes cotidianos, que permitam enraizar-se na cultura do povo uma postura antimanicomial.

O perfil da equipe será necessariamente multiprofissional, integrando profissionais de outros campos do conhecimento, como, por exemplo, os trabalhadores da arte, cultura e educação. Sua proposta pedagógica será dinâmica, permanentemente construída e continuada. A supervisão, mecanismo de suporte usado constantemente pelas equipes interventoras, deixará de ser somente um mecanismo de prevenção da saúde mental da equipe, para transformar-se em avaliação da prática profissional e seus resultados, entendida também como formação permanente e fórum recorrente para a discussão sobre o processo e seu impacto na população atingida. A equipe sempre deverá articular os corpos de conhecimento científico e popular, valorizando a atenção informal, como os de associações religiosas, grupos de auto-ajuda, etc., e assim estimulando os espaços de discussões democráticas entre usuários, técnicos, familiares e a comunidade em geral; socializando informações com o fito de contribuir para a otimização do atendimento da rede de serviços; redirecionando as verbas destinadas à rede manicomial para a rede extra-hospitalar e outras experiências alternativas.

Tal proposta não acolhe qualquer idealização utópica que se possa imaginar. Antes, a estratégia que defendo leva em consideração, para a sua implementação, a compreensão de que o processo da doença, assim como o seu tratamento, deve ser visto de uma maneira contextualizada e longe de uma visão comportamentalizada do homem. Que a intervenção não seja anestésica, e sim vitalizadora. E que procure antes mesmo da prática institucional, "libertar o raciocínio, a subjetividade de cada profissional e leigo, da lógica conservadora dos conceitos de doença, tratamento e cura até agora dominantes na psiquiatria" (BRAGA-CAMPOS, 1992).

Temos que defender e incentivar a pesquisa de novas experiências e o compromisso de sempre procurar novos caminhos que levem a uma melhoria na consideração, tratamento e justiça ao doente mental, tendo em mente que "o que geralmente ocorre não é o problema da doença em si, mas a relação que a instituição possui com o doente" (CORBISIER, 1992, p. 6).

Tomar essa atitude é compreender que para superar o modelo manicomial "é necessário analisar o sofrimento psíquico individual como um fenômeno 
que põe em questão simultaneamente a experiência subjetiva singular e o universo social-histórico em que essa experiência emerge e ganha existência para o próprio sujeito e para os outros. Isto por meio de um vocabulário que nomeia e a torna reconhecível, e de práticas que lhe designam um lugar no conjunto de possibilidades oferecidas a seus membros." (BASAGLIA, 1979).

O novo paradigma a perseguir atualmente é a eqüidade e universalização no atendimento da população. "Para uma ordem social onde se considere o desejo, as necessidades e a expressão de todos e de cada um, simultaneamente, são necessários novos tratados e códigos que espelhem as novas relações sociais e institucionais" (PITTA; DELLARI, 1992).

E, se a saúde psíquica é uma questão de grau, tem sua expressão determinada culturalmente e sofre uma normatividade social, então a educação deve se responsabilizar por parte de programas estratégicos que atuem no alargamento da diversidade de pautas existenciais saudáveis. Estes programas devem ocupar os espaços não formais de educação, como pontos chaves de mobilização social. E, finalmente, que "seja o espaço público como um lugar de afirmação do coletivo e de mudança do poder contratual dos cidadãos em sua relação com o Estado". (CONFERÊNCIA NACIONAL DE SAÚDE, 1987). Isto é, queremos dizer da necessidade de uma nova ética nas relações dos poderes constituídos e a sociedade e de um sujeito para outro sujeito.

\section{REFERÊNCIAS}

BASAGLIA, F.A. A Instituição Negada. São Paulo: Graal, 1979.

CONFERÊNCIA NACIONAL DE SAÚDE, 8., CONFERÊNCIA DE SAÚDE MENTAL, 1., 1987, Brasília, Centro de documentação do Ministério da Saúde.

BRAGA-CAMPOS, F. C. Reformas no atendimento psiquiátrico. In: . Psicologia e Sáude - repensando práticas. São Paulo: Hucitec, 1992.

CORBISIER, C. Instituições e Psiquiatria. In: AMARANTE, P.; BEZERRA, B. (Orgs.). Psiquiatria sem hospício: contribuição ao estudo da reforma psiquiátrica. Rio de Janeiro: Relume Dumará, 1992.

KAFROUNI, R.; PAN, M. A inclusão de alunos com necessidades educativas especiais e os impasses frente a capacitação dos profissionais da educação básica: um estudo de caso. Revista Interação, Curitiba, v. 5, jan./dez. 2001. 
LAGACHE D. A psicanálise. São Paulo: Difusão Européia do Livro, 1966.

MANNONI, M. A criança sua doença e os outros. Rio de Janeiro: Guanabara Koogan, 1990.

MILLOT, C. Freud antipedagogo. Rio de Janeiro: Zahar, 1987.

PAIN, S. Diagnóstico e tratamento dos problemas de aprendizagem. Porto Alegre: Artes Médicas, 1992.

PITTA, A. M. F.; DALLARI, S. G. A cidadania dos doentes mentais no sistema de saúde do Brasil. In: CONFERÊNCIA DE SAÚDE MENTAL, 2., 1992, Brasília. Caderno... Centro de documentação do Ministério da Saúde.

Texto recebido em 12 maio 2003 Texto aprovado em $15 \mathrm{dez} .2003$ 